\title{
Impaired neutrophil actin assembly causes persistent CD11b expression and reduced primary granule exocytosis in Type II diabetes
}

\author{
A. Advani, S. M. Marshall, T. H. Thomas \\ Department of Medicine, School of Medicine, University of Newcastle Upon Tyne, UK
}

\begin{abstract}
Aims/hypothesis. Neutrophil dysfunction has a role in the pathogenesis of complications in Type II (non-insulin-dependent) diabetes mellitus. Neutrophils adhere through expression of the $\beta_{2}$ integrin $\mathrm{CD} 11 \mathrm{~b} / \mathrm{CD} 18$ which closely associates with the actin cytoskeleton. The aim of this study was to investigate the effect of actin polymerisation on CD11b expression and exocytosis of the primary granule marker CD69 in neutrophils from patients with Type II diabetes.

Methods. Neutrophils were activated with fMLP or PMA, actin polymerisation was inhibited with cytochalasin D. Cells were stained for CD11b and CD69 expression and intracellular F-actin was measured with phalloidin-FITC. Cellular fluorescence was measured by flow cytometry. Actin content of Triton X100 fractions of cells was measured by SDS-PAGE and Coomassie blue staining.

Results. PMA caused an increase in neutrophil F-actin that was greater in control subjects than in patients
\end{abstract}

with Type II diabetes $(50.8 \%$ vs $33.4 \%, p<0.001)$ and correlated with actin integrated optical density (IOD) by SDS-PAGE $(r=0.74, p=0.01)$. Loss of CD11b from cell surfaces only occurred in neutrophils with high Factin. The proportion of cells losing CD11b was lower in patients than in control subjects $(23.1 \%$ vs $37.5 \%$, $p<0.001)$ and lowest in patients with additional cardiovascular risk markers $(20.1 \%$ vs $27.7 \%$; $p<0.05)$. Cytochalasin D prevented loss of CD11b $(p<0.001)$. CD69 expression was reduced in patients with Type II diabetes $(22.6 \%$ vs $36.4 \%, p<0.001)$ and correlated with F-actin content $(r=0.78, p<0.0001)$.

Conclusion/interpretation. In Type II diabetes impaired neutrophil actin polymerisation leads to persistent expression of $\mathrm{CD} 11 \mathrm{~b}$ and reduced exocytosis of primary granules and could contribute to the pathogenesis of diabetic complications. [Diabetologia (2002) 45:719-727]

Keywords CD11b/CD18, Type II diabetes, cardiovascular disease, cytoskeleton, neutrophil.
Received: 18 October 2001 / Revised: 11 January 2002 Published online: 4 April 2002

(C) Springer-Verlag 2002

Coresponding author: Dr. T. H. Thomas, Department of Medicine, Medical School, University of Newcastle Upon Tyne, Framlington Place, Newcastle Upon Tyne NE2 4HH, United Kingdom, e-mail: T.H.Thomas@ncl.ac.uk

Abbreviations: NC, Normal control; DM2, all Type II diabetes; $\mathrm{DM} 2+\mathrm{C}$, Type II diabetes with additional cardiovascular risk markers; DM2-, Type II diabetes without additional cardiovascular risk markers; PMA, phorbol 12 myristate 13 acetate; IOD, integrated optical density; PAGE, polyacrylamide gel electrophoresis; fMLP, formyl-methionyl-leucyl-phenylalanine
Circulating neutrophils play a critical part in the host defence against infection. For many years, the increased incidence of bacterial infection in Type II (non-insulin-dependent) diabetes mellitus has been postulated to be caused by an abnormality in neutrophil function [1, 2, 3, 4]. In addition, Type II diabetes is also a major risk factor for cardiovascular disease [5] and neutrophils contribute to acute and chronic myocardial injury [6]. Thus anti-neutrophil antiserum reduces infarct size and the extent of injury after ischaemia-reperfusion $[7,8]$. Neutrophil activation occurs at sites of endothelial injury during coronary angioplasty and contributes to the development of restenosis $[9,10]$. Type II diabetes is associated with both an 
increased incidence of coronary artery restenosis [11, $12]$ and an exaggerated inflammatory response to organ ischaemia-reperfusion injury $[13,14,15,16]$. Neutrophils also influence the pathogenesis of microvascular complications, in particular diabetic retinopathy $[17,18]$.

The presence of vascular complications in diabetes could also contribute to worsened neutrophil function. Both spontaneous neutrophil adherence and fMLP-induced aggregation of neutrophils are associated with the presence of diabetic complications and in particular overt proteinuria $[16,18]$. Recently, an association has been identified between neutrophil elastase content, the concentration of glycaemia and angiopathy in diabetes $[19,20]$.

Cell surface integrins, such as CD11b/CD18, mediate the localisation of neutrophils at sites of injury and transduce signals across cell membranes [21, 22]. When inflammatory stimuli are encountered, circulating neutrophils adhere to the vascular wall and transmigrate into the extravascular space [23]. Upon encountering a pathogen, neutrophils release proteases which are stored in multiple granular compartments and superoxide anion which is generated by the transmembrane NADPH oxidase. The presence of neutrophils with large amounts of CD11b/CD18 on the cell surface will increase neutrophil adhesion to vascular endothelium and potentiate vascular damage. The inability to exocytose primary granules will increase the risk of infection.

We have shown that neutrophils from patients with Type II diabetes have abnormal expression of cell-surface markers in response to phorbol ester stimulation. There is an abnormally large proportion of cells that continue to express integrin CD11b/CD18 at the cell membrane and a failure of cells to exocytose the antigen CD69 [24]. CD69 is contained within primary granules and its expression on neutrophil surfaces indicates that exocytosis of primary granules has occurred [25].

Integrin CD11b/CD18 interacts with cytoskeletal proteins [26, 27] and transmits signals intracellularly through its association with the cytoskeleton. Remodelling of the actin cytoskeleton has been shown to cause both up-regulation and down-regulation of $\mathrm{CD} 11 \mathrm{~b} / \mathrm{CD} 18$ [28]. The globular actin molecule (G-actin) can polymerise to form filamentous actin (F-actin) and this process controls changes in cell shape and motility. The function of the NADPH-oxidase system which produces superoxide and is abnormal in Type II diabetes depends on the ability of neutrophils to organise actin filaments $[29,30]$.

This study examines the hypothesis that a failure in actin polymerisation in neutrophils from Type II diabetic patients is the cause of their inability to downregulate $\mathrm{CD} 11 \mathrm{~b} / \mathrm{CD} 18$ and their failure to exocytose primary granules.

\section{Subjects and methods}

Subjects. With the approval of the Joint Ethics Committee of Newcastle and North Tyneside Health Authority, University of Newcastle Upon Tyne and University of Northumbria at Newcastle, patients with Type II diabetes were recruited from the Newcastle Diabetes Centre. All subjects gave their written informed consent. Patients with Type II diabetes had been diagnosed with the disease at 40 years of age or older and had been treated with oral hypoglycaemic agents for at least five years. Of the patients with Type II diabetes, a subgroup $(n=15)$ was recognised with additional complications associated with cardiovascular risk $(\mathrm{DM} 2+\mathrm{C})$ including an arterial blood pressure greater than $140 / 90 \mathrm{mmHg}$ before antihypertensive treatment, a BMI greater than $30.0 \mathrm{~kg} / \mathrm{m}^{2}$ and albumin-to-creatinine ratio greater than $5.0 \mathrm{mg} / \mathrm{mmol}$ on three separate occasions without overt proteinuria. Healthy control subjects were recruited from the local population as well as from the hospital and university staff. Control subjects had fasting plasma glucose of less than $7.0 \mathrm{mmol} / \mathrm{l}$ and arterial blood pressure less than $140 / 90 \mathrm{mmHg}$, had never received antihypertensive treatment and had no family history of Type II diabetes. Subjects were excluded if they showed any clinical evidence of infection. From each subject, venous blood samples were collected into a heparinised glass tube and samples were kept at room temperature until experiments were carried out within $1 \mathrm{~h}$ from venepuncture.

Reagents. All reagents were from Sigma (Poole, UK), except anti-CD11b-PE and anti-CD45-TRIC (Caltag, Calif., USA), Leucoperm, Erythrolyse and non-specific IgG-PE (Serotec, Abingdon, UK), and calibration beads (Dako, Glostrup, Denmark). All antibodies were mouse anti-human.

Preparation of activated cells. Cells were studied basally and after activation with phorbol 12 myristate 13 acetate (PMA) or formyl-methionyl-leucyl-phenylalanine (fMLP). Studies were also done using cells treated with cytochalasin D. Each sample contained $100 \mu \mathrm{l}$ of whole blood and $100 \mu \mathrm{l}$ of PBS with $5 \mathrm{mmol} / \mathrm{l}$ glucose and $5 \mathrm{mmol} / \mathrm{l}$ glutamine added. Samples were incubated at $37^{\circ} \mathrm{C}$ for $30 \mathrm{~min}$ with either PBS alone or PBS and $162 \mathrm{nmol} / \mathrm{l}$ PMA (100 ng/ml). In other experiments samples were initially incubated with $10 \mu \mathrm{mol} / \mathrm{l}$ fMLP or $10 \mu \mathrm{mol} / \mathrm{l}$ cytochalasin D for $30 \mathrm{~min}$ before $162 \mathrm{nmol} / \mathrm{l}$ PMA was added.

Triple-staining of cells with anti-CD11b-PE, anti-CD45-TRIC and phalloidin-FITC. Staining for the leukocyte common antigen CD45 in conjunction with size and light scatter properties was used to identify neutrophils [24]. Fluorescein-conjugated (FITC) phalloidin was used to identify polymerised F-actin filaments. After cellular activation $100-\mu \mathrm{l}$ aliquots were stained with $1 \mu \mathrm{l}$ antiCD11b-PE and $1 \mu \mathrm{l}$ anti-CD45-TRIC (Tri-color) on ice, in the dark for $30 \mathrm{~min}$. Samples were fixed for $15 \mathrm{~min}$ in the dark with $100 \mu$ leucoperm reagent A, washed in PBS and centrifuged at $300 \mathrm{~g}$ for $5 \mathrm{~min}$. The pellet was resuspended in $100 \mu \mathrm{l}$ leucoperm reagent $\mathrm{B}$, with $10 \mu \mathrm{l}$ phalloidin-FITC and incubated at room temperature for $30 \mathrm{~min}$ in the dark. Leucoperm reagent B served to lyse red blood cells and permeabilise leukocytes. Cells were subsequently washed in PBS, centrifuged at $200 \mathrm{~g}$ for $5 \mathrm{~min}$, resuspended in $500 \mu \mathrm{PBS}$ and analysed immediately using a Becton Dickinson FACScan (Becton Dickinson, San Jose, Calif., USA).

Calculation of CD11b and phalloidin-binding sites. Flow cytometry data were analysed using Winmdi 2.8 (Scripps Institute, Calif., USA). To measure the number of CD11b and phalloidin-binding sites, calibration beads with a known number of binding-sites were run by FACScan daily. A standard curve was used to calculate sites according to median cellular fluo- 
Table 1. Clinical characteristics of subjects

\begin{tabular}{|c|c|c|c|c|}
\hline & \multirow[t]{2}{*}{ Control subjects } & \multicolumn{2}{|c|}{ Type II diabetic patients } & \multirow[t]{2}{*}{ Reference ranges } \\
\hline & & DM2- & $\mathrm{DM} 2+\mathrm{C}$ & \\
\hline Age (years) & $57.1(2.6)$ & $62.8(2.1)$ & $63.4(1.9)$ & \\
\hline Duration of diabetes (years) & - & $9.8(2.2)$ & $9.2(1.9)$ & \\
\hline Cigarette smokers $(n)$ & 1 & 1 & 1 & \\
\hline Systolic BP (mmHg) & $131(3.0)$ & $134(2.3)$ & $147(4.9)^{\mathrm{cd}}$ & \\
\hline Diastolic BP (mmHg) & $76(2.0)$ & $80(1.4)$ & $82(2.1)^{\mathrm{e}}$ & \\
\hline Glucose $(\mathrm{mmol} / \mathrm{l})$ & $5.4(0.6)$ & $10.0(0.7)^{\mathrm{f}}$ & $10.7(1.1)^{\mathrm{f}}$ & $4.0-7.0$ \\
\hline $\mathrm{HbA}_{1 \mathrm{c}}(\%)$ & - & $8.0(0.3)$ & $8.7(0.3)$ & $<6.1$ \\
\hline Albumin-to-creatinine ratio (mg/mmol) & - & $1.4(0.3)$ & $33.1(10.8)^{\mathrm{g}}$ & $0.0-3.5$ \\
\hline Serum creatinine $(\mu \mathrm{mol} / \mathrm{l})$ & $90(2.0)$ & $91(3.8)$ & $102(4.5)^{\mathrm{e}}$ & $70-110$ \\
\hline
\end{tabular}

Values are means \pm SEM. ${ }^{\mathrm{a}} p<0.0001$ vs control subjects, ${ }^{\mathrm{b}} p<0.0001$ vs DM2-, ${ }^{\mathrm{c}} p<0.02$ vs control subjects, ${ }^{\mathrm{d}} p<0.05$ vs DM2-, ${ }^{\mathrm{e}}$ $\mathrm{p}<0.05$ vs control subjects, ${ }^{\mathrm{f}} p<0.0001$ vs control subjects, ${ }^{\mathrm{g}} p<0.01$ vs DM2-, ${ }^{\mathrm{h}} p<0.03$ vs control subjects, ${ }^{\mathrm{i}} p<0.001 \mathrm{vs}$ DM2-.

rescence. Non-specific binding of anti-CD11b-PE was accounted for by incubating samples with non-specific IgG-PE.

Primary granule exocytosis. To calculate the percentage of cells expressing CD69, activated cells were stained with antiCD69-PE and anti-CD45-FITC on ice for $30 \mathrm{~min}$. Samples were fixed by adding a tenfold excess of Erythrolyse, washed twice in PBS at $300 \mathrm{~g}$ and $200 \mathrm{~g}$ and resuspended in $500 \mu \mathrm{l}$ PBS before analysis by FACScan.

Preparation of Triton X-100 components of cells. Leukocytes from five patients in each group were prepared by dextran-sedimentation and hypotonic lysis of contaminating erythrocytes, in the presence of $1 \mu \mathrm{mol} / \mathrm{l}$ leupeptin, $1 \mathrm{mmol} / \mathrm{l} \mathrm{EDTA}, 230 \mu \mathrm{mol} / \mathrm{l}$ PMSF and $40 \mu \mathrm{mol} / 1$ phenylarsine oxide. Samples were resuspended in $0.15 \%$ Triton $\mathrm{X}-100$ in $300 \mu \mathrm{mol} / \mathrm{l}$ sucrose containing $1 \mathrm{mmol} / \mathrm{l} \mathrm{MgCl}$ before centrifugation at $20000 \mathrm{~g}$ for $20 \mathrm{~min}$ to separate the cytoskeletal shell from other cell proteins. The Triton X-100 insoluble pellet was resuspended in the presence of $10 \%$ SDS and sonicated for 1 min. Gels of $10.5 \%$ total acrylamide were used in a Bio-Rad mini-protean system with $1 \mathrm{~mm}$ gels and 10 to $15 \mathrm{~mA}$ per gel. Gels were stained with Coomassie brilliant blue [200 mg Coomassie brilliant blue dissolved in 10:26:65 acetic acid:industrial spirit (ethanol denatured with $4 \%$ methanol):water] for $2 \mathrm{~h}$. Gels were then destained in 5:5:90 acetic acid: industrial spirit: water. Scan analysis was done on dried Coomassie stained gels using a BioImage Visage Electrophoresis Gel Analysis System, version 4.6Q (Copyright 1993 Millipore Corporation). Integrated optical densities (IOD) were analysed using Whole Band Analysis, version 2.4.

Statistics. Values were normally distributed and are given as means and standard error of the mean (SEM). The probability of differences between groups was assessed using Student's $t$ test with Bonferroni correction for multiple analyses. A $p$ value of less than 0.05 was considered statistically significant.

\section{Results}

Clinical characteristics. Overall diabetic patients were the same age as the control subjects and had normal plasma creatinine but had higher BMI, blood pressure and blood glucose than the control subjects. One control subject and two diabetic patients were current cigarette smokers. Six diabetic subjects (four DM2+C) had evidence of diabetic retinopathy (any grade). Seven of the patients were receiving insulin treatment, of which five were DM2+C. Diabetic patients had higher plasma triglycerides but lower plasma cholesterol than the control subjects which reflects the use of lipid lowering treatments in the former group (Table 1). Albumin-to-creatinine ratios were greater than the normal range in 15 of the diabetic patients $(\mathrm{DM} 2+\mathrm{C})$ and these patients had higher blood pressure, $\mathrm{BMI}, \mathrm{HbA}_{1 \mathrm{c}}$ and plasma triglycerides than the normoalbuminuric diabetic patients. The remaining 10 diabetic subjects (DM2-) did not differ from the control subjects in terms of age, blood pressure, BMI or plasma creatinine. The clinical characteristics of subjects whose leukocytes were used to prepare triton shells were not different from their respective groups. There was no association between treatment with statins and actin polymerisation within the patient groups. There was also no correlation between either plasma glucose or $\mathrm{HbA}_{1 \mathrm{C}}$ and neutrophil actin polymerisation.

Phorbol ester activation of neutrophils causes an increase in cellular F-actin content. Phalloidin-FITC staining of neutrophils in whole blood showed two populations of cells that were either F-actin ${ }^{l o}$ or F-actinhi (Fig. 1). Under resting conditions most cells had low F-actin (Fig. 1A, C). Activation of neutrophils with $162 \mathrm{nmol} / \mathrm{l} \mathrm{PMA}$ for $30 \mathrm{~min}$, caused a substantial increase in the number of cells forming new actin filaments and hence a shift to F-actin hi (Fig. 1B,D). However, the percentage of neutrophils in control subjects forming new actin filaments was higher than the neu- 
A

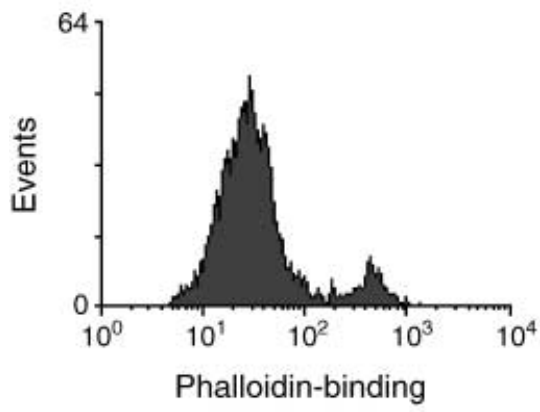

C

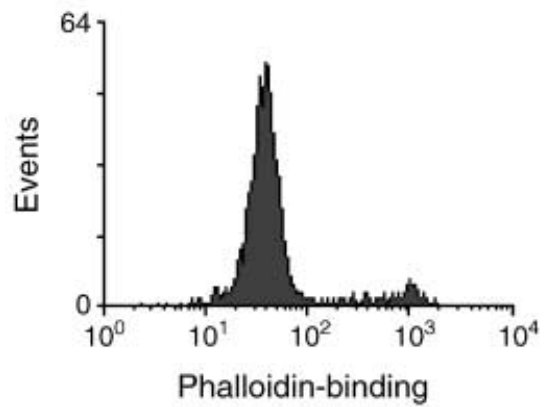

Fig. 1A-D. Flow cytometry histograms showing neutrophil phalloidin-binding. A Control PBS for $30 \mathrm{~min}$; B Control $162 \mathrm{nmol} / \mathrm{l} \mathrm{PMA}$ for $30 \mathrm{~min}$; C Type II diabetes PBS for $30 \mathrm{~min}$; D Type II diabetes $162 \mathrm{nmol} / \mathrm{l}$ PMA for $30 \mathrm{~min}$. Events on the $y$ axis are the number of cells expressing the phalloidin-binding indicated on the $\mathrm{x}$ axis

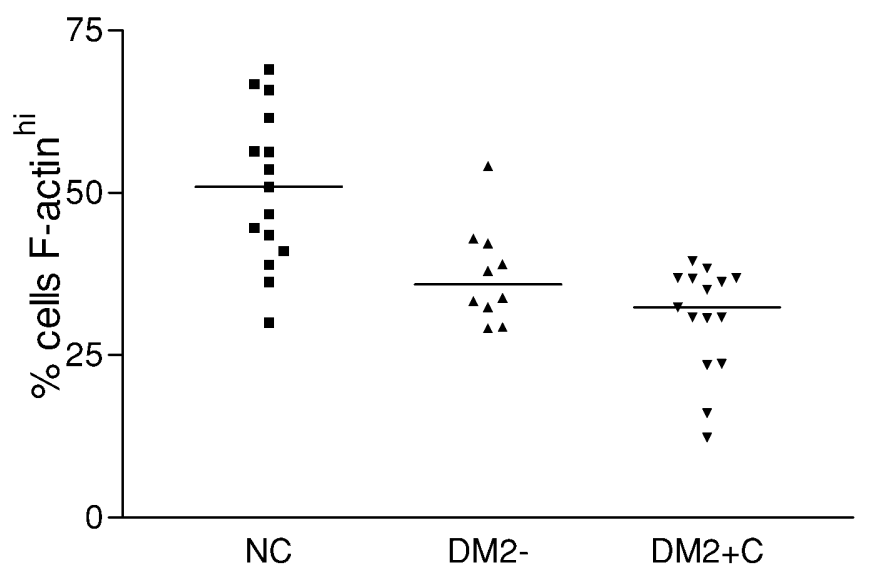

Fig. 2. Percentage of cells F-actin ${ }^{\text {hi }}$ after incubation with $162 \mathrm{nmol} / \mathrm{l}$ PMA for $30 \mathrm{~min}$
B

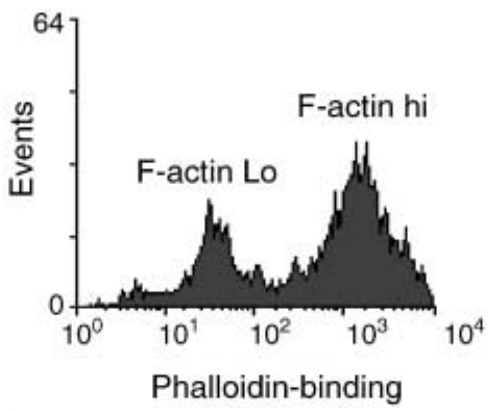

D

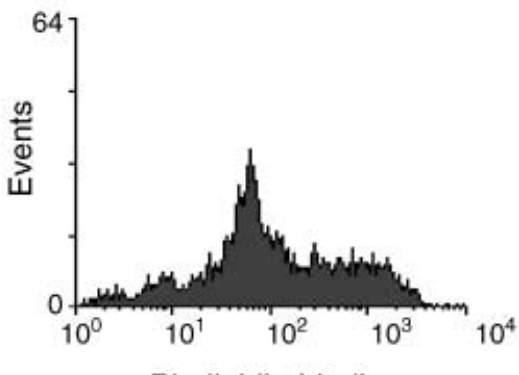

Phalloidin-binding

trophils in patients with Type II diabetes (control subjects: $50.8 \pm 3.1 \%$ cells; Type II diabetic patients: $33.4 \pm 1.8 \%$ cells, $p<0.001$ ) (Fig. 1,2 ). There was no difference in the percentage of cells F-actinhi between DM2 - and DM2+C. PMA also caused an increase in the number of phalloidin-binding sites in cells F-actin ${ }^{\text {hi }}$ in all subject groups (Table 2).

Dual staining of neutrophils, for F-actin and CD11b, after PMA activation showed three populations of cells (Fig. 3). All neutrophils F-actinlo had high surface CD11b. Neutrophils F-actin hi were heterogeneous with either high or low CD11b expression-F-actin ${ }^{\text {hi }} \mathrm{CD} 11 \mathrm{~b}{ }^{\text {hi }}$ or $\mathrm{F}$-actin ${ }^{\text {hi }} \mathrm{CD} 11 \mathrm{~b}^{\text {lo }}$. All cells expressing low CD11b had high F-actin. The percentage of cells F-actinhiCD11b ${ }^{\text {lo }}$ in Type II diabetic patients was lower than in control subjects $(23.1 \pm 1.9 \%$ vs $37.5 \pm 1.8 \%, p<0.001)$. Furthermore, in $\mathrm{DM} 2+\mathrm{C}$ the percentage of $\mathrm{F}$-actin ${ }^{\mathrm{C}} \mathrm{CD} 11 \mathrm{~b} \mathrm{~b}^{\text {lo }}$ neutrophils was lower than in Type II diabetic patients without additional risk factors (DM2-) (Table 3).

Cells stained and fixed directly had similar CD11b expression (58056 \pm 1991 CD11b sites) as those undergoing permeabilisation $(61339 \pm 6066$ CD11b sites $)$,

Table 2. Phalloidin-binding sites for neutrophils in regions F-actin ${ }^{\text {lo }}$ and F-actin ${ }^{\text {hi }}$ after incubation with PBS or 162 nmol/l PMA for $30 \mathrm{~min}$

\begin{tabular}{|c|c|c|c|c|c|c|}
\hline & \multicolumn{3}{|c|}{ F-actin ${ }^{\mathrm{lo}}\left(\times 10^{3}\right.$ sites $)$} & \multicolumn{3}{|c|}{ F-actin ${ }^{h i}\left(\times 10^{3}\right.$ sites $)$} \\
\hline & Control subjects & DM2- & $\mathrm{DM} 2+\mathrm{C}$ & Control subjects & DM2- & $\mathrm{DM} 2+\mathrm{C}$ \\
\hline PBS & $13.1 \pm 1.0$ & $13.4 \pm 1.4$ & $12.0 \pm 1.2$ & $155 \pm 19^{a}$ & $156 \pm 27^{a}$ & $171 \pm 21^{\mathrm{a}}$ \\
\hline PMA & $10.0 \pm 0.8$ & $13.3 \pm 2.8$ & $10.3 \pm 1.5$ & $271 \pm 25^{b}$ & $288 \pm 35^{\mathrm{b}}$ & $275 \pm 26^{b}$ \\
\hline
\end{tabular}

${ }^{\mathrm{a}} p<0.001$ vs F-actin ${ }^{\mathrm{lo}} \mathrm{PBS},{ }^{\mathrm{b}} p<0.05$ vs F-actin hi PBS 


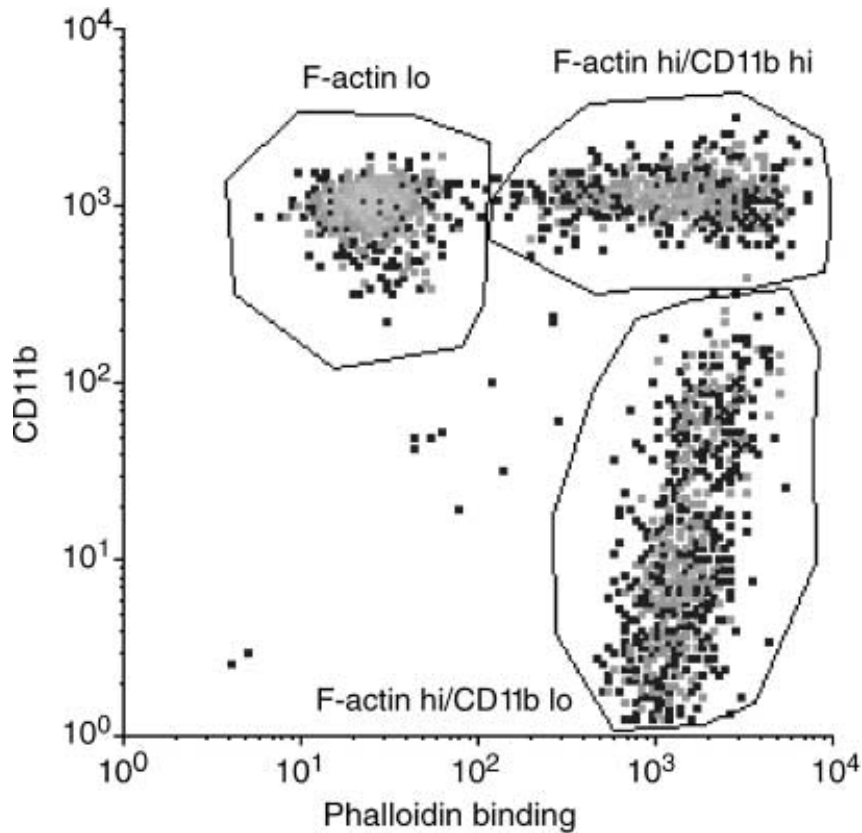

Fig. 3. Density plot of neutrophils from a control subject after dual staining with anti-CD11b-PE and phalloidin-FITC after incubation with $162 \mathrm{nmol} / \mathrm{l}$ PMA for $30 \mathrm{~min}$ confirming that the permeabilisation step did not affect labelling of CD11b.

Reduced CDIIb expression associated with F-actin formation occurs through down-regulation. To test the hypothesis that incubation with PMA for 30 min causes neutrophils to down-regulate surface CD11b expression, cells were pre-incubated with the chemotactic peptide fMLP. fMLP caused all cells initially to express high CD11b (Fig. 4A, B). When samples were subsequently activated with PMA, three populations could be observed as seen for PMA alone (Fig. 4C, Table 4). As fMLP-activated neutrophils had high surface CD11b the appearance of cells F-actin ${ }^{\text {hi }} \mathrm{CD} 11 \mathrm{~b}^{\text {lo }}$ after stimulation with PMA shows that PMA causes CD11b to be lost from the cell surface.

Consistent with results for PMA alone, more cells were F-actinhiCD11b in the control subjects than in either DM2+C or DM2- after incubation with both

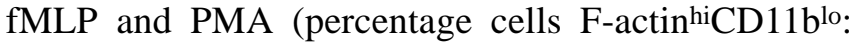
control subjects, $31.5 \pm 2.0 \%$; DM2-, 28.4 $\pm 1.3 \%$; $\mathrm{DM} 2+\mathrm{C}, 21.1 \pm 1.5 \%$ ( $p<0.001$ vs control subjects).
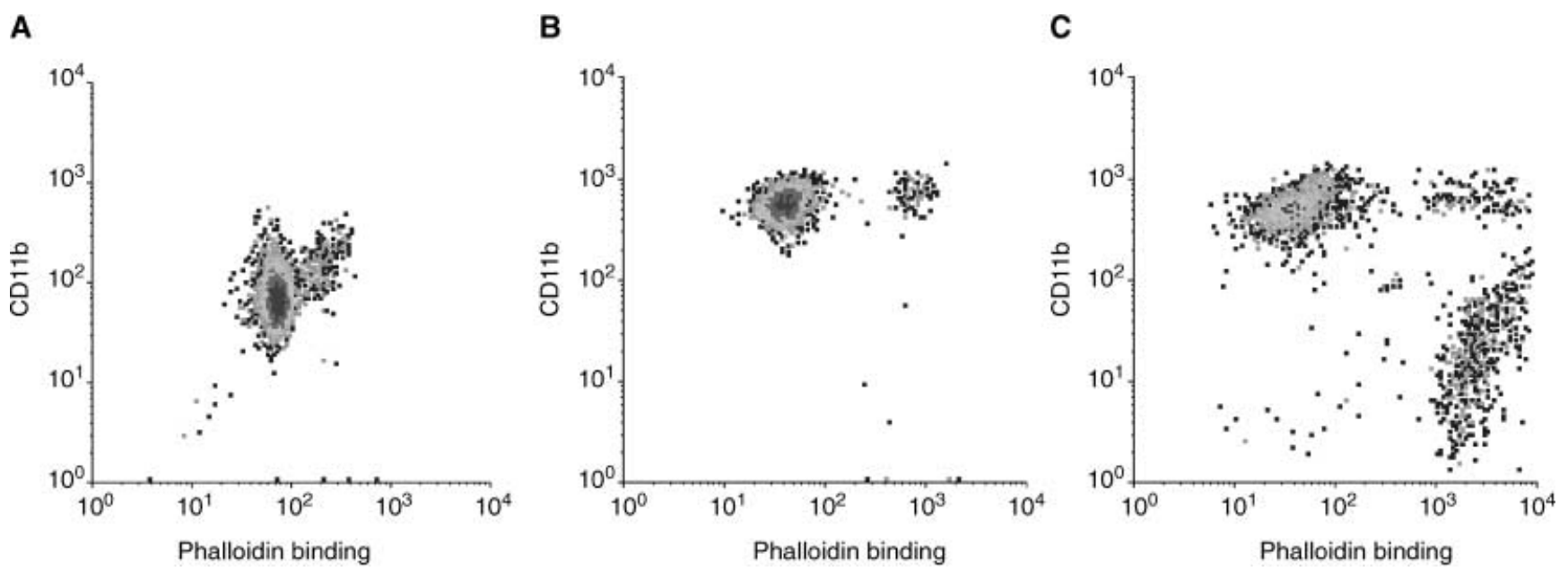

Fig. 4A-C. Density plots of neutrophils from control subjects after incubation with PBS for $30 \mathrm{~min}$ (A), $10 \mu \mathrm{mol} / \mathrm{l} \mathrm{fMLP}$ for $30 \mathrm{~min}(\mathbf{B})$ and $10 \mu \mathrm{mol} / 1 \mathrm{fMLP}$ for $30 \mathrm{~min}$ before $162 \mathrm{nmol} / \mathrm{l}$ PMA for $30 \mathrm{~min}(\mathbf{C})$

Table 3. Percentage of cells and anti-CD11b binding sites for cells in regions F-actin ${ }^{\text {lo }}$, F-actin ${ }^{\text {hi }}$ CD $11 b^{\text {hi }}{ }^{\text {and }}$ F-actin ${ }^{\text {hi }}$ CD $11 b^{\text {lo }}$ after incubation with $162 \mathrm{nmol} / \mathrm{l}$ PMA for $30 \mathrm{~min}$

\begin{tabular}{|c|c|c|c|c|c|c|}
\hline & \multicolumn{3}{|l|}{$\%$ cells } & \multicolumn{3}{|c|}{ CD11b sites $\left(\times 10^{3}\right)$} \\
\hline & F-actinlo & F-actinhiCD11b ${ }^{\text {hi }}$ & F-actinhiCD $11 b^{\text {lo }}$ & F-actin ${ }^{\text {lo }}$ & F-actinhiCD11b ${ }^{\text {hi }}$ & F-actinhi $C D 11 b^{\text {lo }}$ \\
\hline DM2- & $60.7 \pm 3.2$ & $11.6 \pm 1.7$ & $27.7 \pm 1.8^{b}$ & $44 \pm 5$ & $39 \pm 6$ & $0.4 \pm 0.2^{\mathrm{a}}$ \\
\hline $\mathrm{DM} 2+\mathrm{C}$ & $66.7 \pm 2.8$ & $13.2 \pm 1.6$ & $20.1 \pm 1.9^{c}$ & $52 \pm 5$ & $44 \pm 3$ & $0.7 \pm 0.4^{\mathrm{a}}$ \\
\hline
\end{tabular}

a $p<0.0001$ vs CD11b sites F-actin ${ }^{10}$

${ }^{\mathrm{b}} p<0.01$ vs \%Control subjects cells F-actin ${ }^{\text {hiCD }} 11 b^{\text {lo }}$

${ }^{\mathrm{c}} p<0.05$ vs $\% \mathrm{DM} 2-$ cells $\mathrm{F}$-actin ${ }^{\mathrm{hi}} \mathrm{CD} 11 \mathrm{~b}^{\text {lo }}$ 
Table 4. Effect of fMLP on neutrophil F-actin and CD11b expression. Neutrophils from control subjects $(n=15)$ were incubated with PBS for $30 \mathrm{~min}(\mathrm{PBS}), 10 \mu \mathrm{mol} / \mathrm{l}$ fMLP for $30 \mathrm{~min}$
(fMLP) or $10 \mu \mathrm{mol} / \mathrm{l}$ fMLP for $30 \mathrm{~min}$ before $162 \mathrm{nmol} / \mathrm{l}$ PMA for $30 \mathrm{~min}$ (fMLP/PMA)

\begin{tabular}{|c|c|c|c|c|c|c|}
\hline & \multicolumn{3}{|l|}{$\%$ cells } & \multicolumn{3}{|c|}{ CD11b sites $\left(\times 10^{3}\right)$} \\
\hline & F-actin ${ }^{\text {lo }}$ & F-actinhiCD11b ${ }^{h i}$ & F-actinhiCD11b ${ }^{\text {lo }}$ & F-actin ${ }^{10}$ & F-actinhiCD11b ${ }^{\text {hi }}$ & F-actin ${ }^{\text {hi }}$ CD $11 b^{\text {lo }}$ \\
\hline FMLP & $72.9 \pm 3.7$ & $13.8 \pm 1.5$ & $13.3 \pm 2.8$ & $42 \pm 7$ & $32 \pm 4$ & $0.1 \pm 0.1^{\mathrm{a}}$ \\
\hline fMLP:PMA & $54.8 \pm 3.1$ & $13.7 \pm 1.8$ & $31.5 \pm 2.0^{\mathrm{b}}$ & $43 \pm 6$ & $36 \pm 5$ & $0.2 \pm 0.2^{\mathrm{a}}$ \\
\hline
\end{tabular}

${ }^{\mathrm{a}} p<0.0001$ vs CD11b sites F-actin ${ }^{\mathrm{lo}},{ }^{\mathrm{b}} p=0.001$ vs $\%$ cells F-actinhiCD $11 \mathrm{~b}^{\text {lo }}$ with fMLP

Table 5. Percentage of cells F-actin ${ }^{\mathrm{lo}}$, F-actinhiCD11b ${ }^{\text {hi }}$ and F-actinhiCD11b ${ }^{\text {lo }}$ after incubation with $10 \mu \mathrm{mol} / \mathrm{l}$ cytochalasin D for 30 min before $162 \mathrm{nmol} / \mathrm{l}$ PMA for $30 \mathrm{~min}$. Percentage of cells in each region for control subjects $162 \mathrm{nmol} / \mathrm{l}$ PMA for $30 \mathrm{~min}$ for comparison

\begin{tabular}{lccc}
\hline & F-actin $^{\text {lo }}$ & F-actin $^{\text {hiCD11b }}$ & F-actin $^{\text {hi }}$ \\
\hline Control subjects (PMA) & $51.1 \pm 2.6$ & $11.4 \pm 2.0$ & $37.5 \pm 1.8$ \\
Control subjects (CD/PMA) & $76.6 \pm 1.8$ & $8.7 \pm 1.1$ & $14.7 \pm 1.2^{\mathrm{a}}$ \\
DM2- (CD/PMA) & $81.5 \pm 3.2$ & $6.5 \pm 1.1$ & $12.0 \pm 1.0^{\mathrm{a}}$ \\
DM2+C (CD/PMA) & $85.3 \pm 2.3$ & $6.5 \pm 1.1$ & $8.2 \pm 0.8^{\mathrm{a}}$ \\
\hline
\end{tabular}

a $p<0.001$ vs $\%$ cells F-actin ${ }^{\text {hi CD}} 11 b^{\text {lo }}$ with PMA

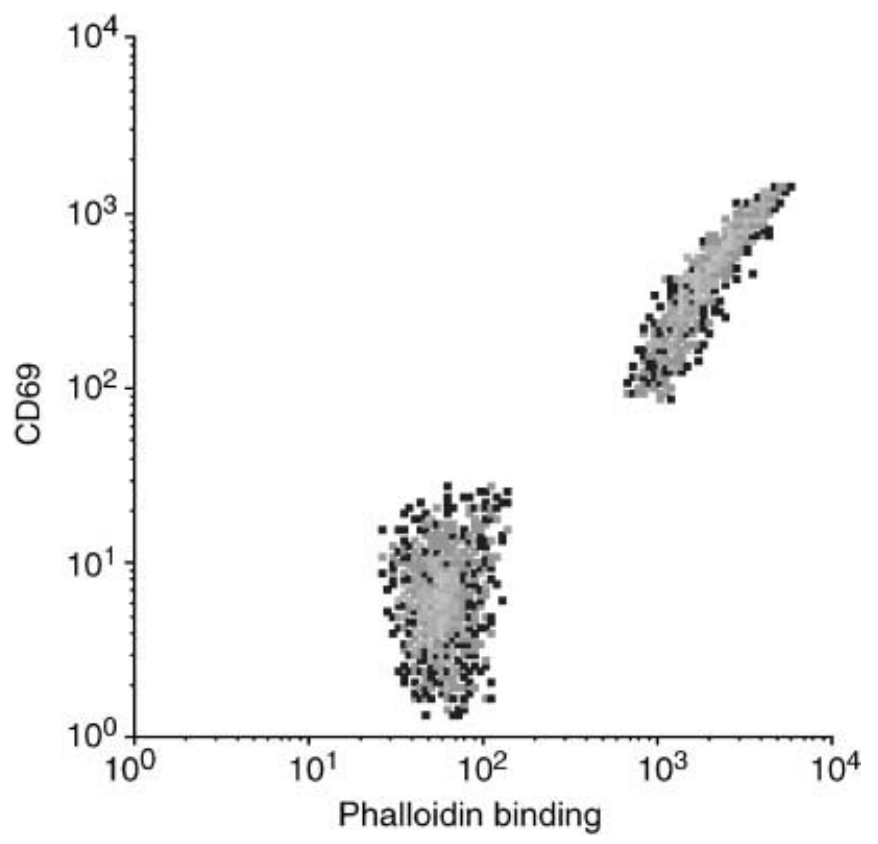

Fig. 5. Density plot of neutrophils from control subjects after incubation with $162 \mathrm{nmol} / \mathrm{l} \mathrm{PMA}$ for $30 \mathrm{~min}$ and stained with phalloidin-FITC and anti-CD69-PE

Neutrophil F-actin formation is associated with primary granule exocytosis. Consistent with our previous observations, CD69 expression was reduced in all Type II diabetic patients compared with the control subjects (percentage cells expressing CD69 after incubation with $162 \mathrm{nmol} / \mathrm{l}$ PMA for $30 \mathrm{~min}$ : control subjects, 36.4 $\pm 2.6 \%$; DM2-, 25.4 $\pm 1.4 \%$; DM $2+\mathrm{C}$, $=21.0 \pm 3.8 \% ; p<0.001$ vs control subjects). In all subject groups there was a strong correlation between the percentage of cells CD69 positive and the percentage of cells F-actinhi $(r=0.78, p<0.0001)$. Dual-staining of neutrophils with both phalloidin-FITC and CD69-PE confirmed that only cells with high intracellular F-actin expressed CD69 (Fig. 5).

Actin content of Triton X-100 insoluble components of cells correlates with phalloidin binding. Triton X-100 was used to prepare cytoskeletal fractions of leukocytes that had been incubated with PMA. After SDSPAGE and Coomassieblue-staining, the IOD of the $44,000 \mathrm{M}_{\mathrm{r}}$ actin band correlated strongly with the proportion of neutrophils F-actin hi identified by phalloidin-FITC staining $(r=0.74, p<0.01)$ (Fig. 6).

Inhibition of actin polymerisation with cytochalasin $D$ prevents $C D 11 b$ down-regulation. Cells were pretreated with cytochalasin D $(10 \mu \mathrm{mol} / \mathrm{l})$ before activation with PMA to elucidate the effect of cytoskeletal disruption on CD11b expression. In all groups pre-incubation of cells with cytochalasin D prevented the increase induced by phorbol ester in the proportion of cells $\mathrm{F}$-actinhi $(p<0.001)$. This was associated with a reduction in the percentage of cells F-actin hi CD $11 b^{\text {lo }}$ (Table 5).

\section{Discussion}

Labelling actin filaments with phalloidin-FITC showed that PMA stimulation caused a marked increase in actin polymerisation in neutrophils. However, a much lower proportion of neutrophils were able to increase actin polymerisation in Type II diabetic pa- 


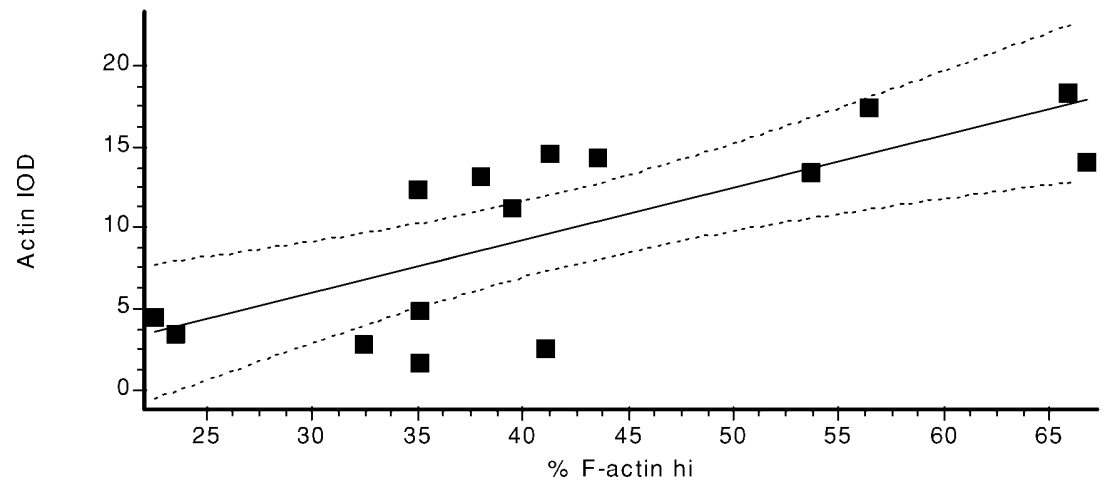

Fig. 6. Correlation between percentage of cells F-actin ${ }^{\text {hi }}$ detected by phalloidin-FITC staining and IOD for actin in Triton $\mathrm{X}-100$ insoluble fractions of leukocytes after incubation with $162 \mathrm{nmol} / \mathrm{l} \mathrm{PMA}$ for $30 \mathrm{~min}(r=0.74, p<0.01)$

tients than in healthy subjects. The impaired actin polymerisation in Type II diabetes was a major factor in the inability of their neutrophils to down-regulate integrin $\mathrm{CD} 11 \mathrm{~b} / \mathrm{CD} 18$ and to exocytose primary granules (CD69).

The greater PMA stimulated polymerisation of actin into the cytoskeletal fraction of neutrophils from control subjects compared with Type II diabetic patients was confirmed by the estimation of the actin content of the Triton X-100 insoluble cytoskeleton of cells. This showed an increase in actin content after PMA stimulation and correlated with the percentage of neutrophils with increased actin filaments which were identified by flow cytometry.

CD11b exocytosis is an early event in neutrophil activation that upon PMA stimulation is followed by primary granule exocytosis and $\mathrm{CD} 11 \mathrm{~b}$ down-regulation. All neutrophils incubated with fMLP for $30 \mathrm{~min}$ expressed high CD11b at the cell membrane, without an increase in intracellular F-actin above baseline values. Therefore, subsequent stimulation with PMA that caused the appearance of neutrophils with low CD11b must have resulted from a process of CD11b downregulation that occurred only in cells forming new actin filaments.

In support of a causal relation between actin polymerisation and both primary granule exocytosis and CD11b down-regulation, both processes were inhibited by cytochalasin $\mathrm{D}$, which binds to the barbed ends of actin filaments inhibiting association and disassociation of actin monomers.

This study also confirms our previous observation that PMA stimulated CD11b exocytosis is normal in neutrophils from Type II diabetic patients but that subsequent $\mathrm{CD} 11 \mathrm{~b}$ down-regulation and primary granule exocytosis are much impaired. We have shown that the latter events are dependent on the formation of actin filaments. Therefore, the impaired actin polymerisation in neutrophils from Type II diabetic patients is the primary abnormality that causes the abnormal CD11b down-regulation and primary granule exocytosis. As increased CD11b expression can contribute to cardiovascular disease, those patients with the additional cardiovascular disease risk markers of hypertension and microalbuminuria were examined separately. These patients had a smaller proportion of neutrophils that were able to down-regulate CD11b than patients with diabetes and no additional risk markers.

Within the group of diabetic subjects abnormal neutrophil actin polymerisation and CD11b expression was not related to either plasma glucose or glycated haemoglobin though the study was not designed specifically to test this hypothesis. A recent report of an inverse association between neutrophil lysosomal-enzyme secretion, leukotriene B4 production and glycaemia [31] reflected the difference between diabetic and normal subjects. Therefore, in both studies, the only clear association with neutrophil dysfunction is the presence or absence of diabetes rather than indicators of the severity of disordered glucose homeostasis within Type II diabetes.

Although our study was conducted using the experimental agent phorbol ester, CD11b loss from the cell surface has also been induced using a multiple receptor stimulation with fMLP, granulocyte-macrophage colony stimulating factor (GM-CSF) and platelet factor 4 (PF4) [32]. It is not likely that the F-actin ${ }^{l o} \mathrm{CD} 11 \mathrm{~b}{ }^{\text {hi }}$, Factin ${ }^{\text {hi }} \mathrm{CD} 11 \mathrm{~b}^{\text {hi }}$ and $\mathrm{F}$-actin ${ }^{\text {hi }} \mathrm{CD} 11 \mathrm{~b}^{\text {lo }}$ sub-populations of neutrophils are different subsets of neutrophils in patients, as baseline neutrophil characteristics did not differ between groups. The heterogeneity of F-actinhi neutrophils in their expression of CD11b suggests that actin polymerisation is necessary and yet not sufficient to allow CD11b down-regulation. Thus in healthy subjects $77 \%$ of $\mathrm{F}$-actin ${ }^{\text {hi }}$ neutrophils lost CD11b but in DM2+C only $60 \%$ did so. The cellular pathways that allow some F-actinhi cells to become CD11b ${ }^{\text {lo }}$ and others to remain CD11bhi are not clear but could be important in defining additional cardiovascular risk among patients with Type II diabetes.

Most neutrophil functions occur in adherent cells, a process that occurs through the action of $\beta_{2}$ integrins, including $\mathrm{CD} 11 \mathrm{~b} / \mathrm{CD} 18$. Cross-linking of CD18 on neutrophil surfaces induces a number of cellular events including an increase in intracellular calcium, 
exocytosis of primary granules, shedding of L-selectin and actin polymerisation [33]. In Type II diabetes, the consequences of impaired neutrophil actin filament formation include persistent integrin expression and impaired primary granule exocytosis. Loss of CD11b in response to cellular activation with phorbol ester is associated with loss of cellular adhesion to ICAM-1 and fibrinogen [32]. In patients with Type II diabetes and especially those who also have hypertension, microalbuminuria and a high BMI, persistent CD11b expression could contribute to the burden of cardiovascular disease through increased neutrophil adhesion at sites of vascular injury. Adherent neutrophils release proteases and superoxide anion as well as acting as a nidus for platelet aggregation and affecting vasomotor tone $[6,34,35,36]$. Increased $\mathrm{CD} 11 \mathrm{~b}$ expression has been found during ischaemia-reperfusion injury [13, $14,15]$ and at sites of coronary restenosis $[9,10]$, two conditions that occur with increased frequency in diabetes. It is possible that a failure of neutrophils to polymerise actin could be a factor in the adverse outcomes of these complications.

Neutrophil dysfunction also contributes to the increased incidence of bacterial infection in Type II diabetes. Both neutrophil superoxide production and primary granule exocytosis are important features of the immune response to bacterial infection and both are abnormal in Type II diabetes [3, 24]. Previous studies have shown a requirement for cytoskeletal reorganisation in the normal functioning of the NADPH oxidase complex $[29,30]$. We have shown that a failure to remodel the actin cytoskeleton is associated with a failure of neutrophils to release primary granules in addition to increased surface integrin expression.

In conclusion, our data suggest that actin polymerisation is required for both loss of integrin CD11b from neutrophil cell surfaces and neutrophil primary granule exocytosis. Furthermore, actin polymerisation is impaired in Type II diabetes and underlies the defect in integrin expression which is most marked in subjects at highest cardiovascular risk. Impaired neutrophil actin polymerisation could contribute to the increased incidence of cardiovascular disease and bacterial infection in Type II diabetes.

Acknowledgements. The authors are indebted to Mrs V. Mott and Mrs A. Taylor for their technical assistance. A. Advani is a Hypertension Trust Clinical Research Fellow. T.H. Thomas is supported by the Northern Counties Kidney Research Fund.

\section{References}

1. Bagdade JD, Root RK, Bulger RJ (1974) Impaired leukocyte function in patients with poorly controlled diabetes. Diabetes 23: 9-15

2. Nolan CM, Beaty HN, Bagdade JD (1978) Further characterization of the impaired bactericidal function of granulocytes in patients with poorly controlled diabetes. Diabetes 27: 889-894
3. Shah SV, Wallin JD, Eilen SD (1983) Chemiluminescence and superoxide anion production by leukocytes from diabetic patients. J Clin Endocrinol Metab 57: 402-409

4. Tan JS, Anderson JL, Watanakunakorn C, Phair JP (1975) Neutrophil dysfunction in diabetes mellitus. J Lab Clin Med 85: 26-33

5. Diabetes mellitus: a major risk factor for cardiovascular disease. (1999) A joint editorial statement by the American Diabetes Association; The National Heart, Lung, and Blood Institute; The Juvenile Diabetes Foundation International; The National Institute of Diabetes and Digestive and Kidney Diseases; and The American Heart Association. Circulation 100: 1132-1133

6. Ricevuti G, Mazzone A, Pasotti D, De Servi S, Specchia G (1991) Role of granulocytes in endothelial injury in coronary heart disease in humans. Atherosclerosis 911-14

7. Romson JL, Hook BG, Kunkel SL, Abrams GD, Schork MA, Lucchesi BR (1983) Reduction of the extent of ischemic myocardial injury by neutrophil depletion in the dog. Circulation 67: 1016-1023

8. Schmid-Schonbein GW, Seiffge D, DeLano FA, Shen K, Zweifach BW (1991) Leukocyte counts and activation in spontaneously hypertensive and normotensive rats. Hypertension 17: 323-330

9. Inoue T, Sakai Y, Fujito T, Hoshi K, Hayashi T, Takayanagi K, Morooka S (1998) Clinical significance of neutrophil adhesion molecules expression after coronary angioplasty on the development of restenosis. Thromb Haemost 79: 5458

10. Inoue T, Sakai Y, Morooka S, Hayashi T, Takayanagi K, Takabatake Y (1996) Expression of polymorphonuclear leukocyte adhesion molecules and its clinical significance in patients treated with percutaneous transluminal coronary angioplasty. J Am Coll Cardiol 28:1127-1133

11. Levine GN, Jacobs AK, Keeler GP et al. (1997) Impact of diabetes mellitus on percutaneous revascularization (CAVEAT- I). CAVEAT-I Investigators. Coronary Angioplasty Versus Excisional Atherectomy Trial. Am J Cardiol 79: 748-755

12. Van Belle E, Bauters C, Hubert E et al. (1997) Restenosis rates in diabetic patients: a comparison of coronary stenting and balloon angioplasty in native coronary vessels. Circulation 96: 1454-1460

13. Panes J, Kurose I, Rodriguez-Vaca D et al. (1996) Diabetes exacerbates inflammatory responses to ischemia-reperfusion. Circulation 93: 161-167

14. Hokama JY, Ritter LS, Davis-Gorman G, Cimetta AD, Copeland JG, McDonagh PF (2000) Diabetes enhances leukocyte accumulation in the coronary microcirculation early in reperfusion following ischemia. J. Diabetes Complications 14: 96-107

15. McDonagh PF, Hokama JY, Copeland JG, Reynolds JM (1997) The blood contribution to early myocardial reperfusion injury is amplified in diabetes. Diabetes 46: 18591867

16. Ohmori M, Harada K, Kitoh Y, Nagasaka S, Saito T, Fujimura A (2000) The functions of circulatory polymorphonuclear leukocytes in diabetic patients with and without diabetic triopathy. Life Sci 66: 1861-1870

17. Lutty GA, Cao J, McLeod DS (1997) Relationship of polymorphonuclear leukocytes to capillary dropout in the human diabetic choroid. Am J Pathol 151: 707-714

18. Takahashi T, Hato F, Yamane T et al. (2000) Increased spontaneous adherence of neutrophils from Type 2 diabetic patients with overt proteinuria: possible role of the progression of diabetic nephropathy. Diabetes Care 23: $417-418$ 
19. Karahan SC, Deger O, Orem A, Ucar F, Erem C, Alver A, Onder E (2001) The effects of impaired trace element status on polymorphonuclear leukocyte activation in the development of vascular complications in Type 2 diabetes mellitus. Clin Chem Lab Med 39: 109-115

20. Piwowar A, Knapik-Kordecka M, Warwas M (2000) Concentration of leukocyte elastase in plasma and polymorphonuclear neutrophil extracts in Type 2 diabetes. Clin Chem Lab Med 38: 1257-1261

21. Newton RA, Thiel M, Hogg N (1997) Signaling mechanisms and the activation of leukocyte integrins. J Leukoc Biol 61: 422-426

22. Willeke T, Behrens S, Scharffetter-Kochanek K, Gaehtgens P, Walzog B (2000) Beta2 integrin (CD11/CD18)-mediated signaling involves tyrosine phosphorylation of $\mathrm{c}-\mathrm{Cbl}$ in human neutrophils. J Leukoc Biol 68: 284-292

23. Springer TA (1994) Traffic signals for lymphocyte recirculation and leukocyte emigration: the multistep paradigm. Cell 76: 301-314

24. Senior PA, Marshall SM, Thomas TH (1999) Dysregulation of PMN antigen expression in Type 2 diabetes may reflect a generalized defect of exocytosis: influence of hypertension and microalbuminuria. J Leukoc Biol 65: 800-807

25. Fardon NJM, Wilkinson R, Thomas TH (2001) Rapid fusion of granules with neutrophil cell membranes in hypertensive patients may increase vascular damage. Am J Hypertens 14: 927-933

26. Hayashi M, Suzuki H, Kawashima S, Saido TC, Inomata M (1999) The behavior of calpain-generated N- and C-terminal fragments of talin in integrin-mediated signaling pathways. Arch Biochem Biophys 371: 133-141

27. Inomata M, Hayashi M, Ohno-Iwashita Y, Tsubuki S, Saido TC, Kawashima S (1996) Involvement of calpain in integrin-mediated signal transduction. Arch Biochem Biophys 328: $129-134$
28. Anderson SI, Hotchin NA, Nash GB (2000) Role of the cytoskeleton in rapid activation of CD11b/CD18 function and its subsequent downregulation in neutrophils. J Cell Sci 113: 2737-2745

29. El Benna J, Dang PM, Andrieu V et al. (1999) P40phox associates with the neutrophil Triton X-100-insoluble cytoskeletal fraction and PMA-activated membrane skeleton: a comparative study with P67phox and P47phox. J Leukoc Biol 66: 1014-1020

30. Tsunawaki S, Yoshikawa K (2000) Relationships of p40(phox) with p67(phox) in the activation and expression of the human respiratory burst NADPH oxidase. J Biochem (Tokyo) 128: 777-783

31. McManus LM, Bloodworth RC, Prihoda TJ, Blodgett JL, Pinckard RN (2001) Agonist-dependent failure of neutrophil function in diabetes correlates with extent of hyperglycaemia. J Leukoc Biol 70: 395-404

32. Davey PC, Zuzel M, Kamiguti AS, Hunt JA, Aziz KA (2000) Activation-dependent proteolytic degradation of polymorphonuclear CD11b. Br J Haemat 111: 934-942

33. Walzog B, Seifert R, Zakrzewicz A, Gaehtgens P, Ley K (1994) Cross-linking of CD18 in human neutrophils induces an increase of intracellular free $\mathrm{Ca} 2+$, exocytosis of azurophilic granules, quantitative up-regulation of CD18, shedding of L-selectin, and actin polymerization. J Leukoc Biol 56: 625-635

34. Cole CW, Hagen PO, Lucas JF et al. (1987) Association of polymorphonuclear leukocytes with sites of aortic catheterinduced injury in rabbits. Atherosclerosis 67: 229-236

35. De Servi S, Ricevuti G, Mazzone A et al. (1991) Granulocyte function in coronary artery disease. Am J Cardiol 68: 64B-68B

36. Prescott MF, McBride CK, Court M (1989) Development of intimal lesions after leukocyte migration into the vascular wall. Am J Pathol 135: 835-846 